Chapman University

Chapman University Digital Commons

Psychology Faculty Books and Book Chapters

Psychology

2005

\title{
Prenatal Stress and Stress Physiology Influences Human Fetal and Infant Development
}

\author{
Elyssia Poggi Davis \\ University of California, Irvine \\ Calvin J. Hobel \\ Cedars Sinai Medical Center \\ Curt A. Sandman \\ University of California, Irvine \\ Laura M. Glynn \\ Chapman University, Iglynn@chapman.edu \\ Pathik D. Wadhwa \\ University of California, Irvine
}

Follow this and additional works at: https://digitalcommons.chapman.edu/psychology_books

Part of the Obstetrics and Gynecology Commons, Other Medical Sciences Commons, and the Reproductive and Urinary Physiology Commons

\section{Recommended Citation \\ Davis EP, Hobel C, Sandman CA, Glynn LM, \& Wadhwa PD. (2005). Prenatal stress and stress physiology influence human fetal and infant development. In J. Schulkin \& M.L. Powers (Eds.), Birth, distress, and disease: Placental-brain interactions (pp. 183-201). Cambridge, UK: Cambridge University Press.}

This Book is brought to you for free and open access by the Psychology at Chapman University Digital Commons. It has been accepted for inclusion in Psychology Faculty Books and Book Chapters by an authorized administrator of Chapman University Digital Commons. For more information, please contact laughtin@chapman.edu. 


\title{
Prenatal stress and stress physiology influences human fetal and infant development
}

\author{
Elysia Poggi Davis ${ }^{1}$, Calvin J. Hobel ${ }^{2}$, Curt A. Sandman, \\ Laura Glynn ${ }^{3}$ and Pathik D. Wadhwa ${ }^{4}$ \\ 1 Department of Psychiatry and Human Behavior, University of California, Irvine, California, USA \\ ${ }^{2}$ Department of Obstetrics and Gynecology, Cedars Sinai Medical Center, Los Angeles, California, USA \\ ${ }^{3}$ Department of Psychiatry and Human Behavior, University of California, Irvine, California, USA \\ ${ }^{4}$ Departments of Psychiatry and Human Behavior, and Obstetrics and Gynecology, University of California, \\ Irvine, California, USA
}

Prenatal stress has been proposed as a risk factor that may have developmental consequences persisting throughout the lifespan. Exposing rodents to stress during pregnancy has consequences for brain development, stress regulation, learning, emotionality (increased anxiety), and social behavior (increased withdrawal) of the offspring (Weinstock, 2001; Chapillon et al., 2002). Additionally, non-human primates who experience stress during pregnancy have offspring with enhanced behavioral reactivity to stressors later in life (Clarke et al., 1994), lowered levels of motor behavior (Schneider, 1992), compromised neuromotor responses (Schneider and Coe, 1993), irritable temperament (Schneider et al., 1992), and attentional problems (Schneider et al., 1999).

Many researchers have focused on the hypothalamic-pituitary-adrenocortical (HPA) axis, one of the body's major stress systems, as a mechanism that may mediate these effects (Ward and Phillips, 2001; Welberg and Seckl, 2001). The HPA axis activity is regulated by the release of hypothalamic corticotropin-releasing hormone $(\mathrm{CRH})$ that stimulates the biosynthesis and release of adrenocorticotropin hormone $(\mathrm{ACTH})$ and $\beta$-endorphin $(\beta E)$ from the anterior pituitary. The release of ACTH triggers the biosynthesis and release of glucocorticoids (cortisol in primates and corticosterone in rodents) from the adrenal cortex. Glucocorticoids are released into the

Corresponding author: Pathik D. Wadhwa, MD, PhD., Behavioral Perinatology Research Program, University of California, Irvine, 3117 Gillespie Neuroscience Research Facility, Irvine, CA 92697. Tel: (949) 824-8238, Fax: (949) 824-8218, E-mail: pwadhwa@uci.edu

Preparation of this manuscript was supported, in part, by US PHS (NIH) grants HD-33506 and HD-41696 to P.D.W. 
general circulation and have effects on nearly every organ and tissue in the body (Munck et al., 1984). Consequences of glucocorticoid release include energy mobilization and immunosuppression (Chrousos and Gold, 1992). Glucocorticoids easily pass through the blood-brain barrier (Zarrow et al., 1970). There are receptors for glucocorticoids throughout the central nervous system (CNS) (de Kloet et al., 1998; Sanchez et al., 2000). Glucocorticoids regulate their own release by negative feedback actions at the hypothalamus and pituitary inhibiting the release of CRH and ACTH. Glucocorticoids additionally act on extrahypothalamic sites including the hippocampus and frontal cortex further activating negative feedback regulation of $\mathrm{CRH}$ production in the hypothalamus (Jacobson and Sapolsky, 1991; Sanchez et al., 2000). In contrast glucocorticoids increase $\mathrm{CRH}$ production in extrahypothalamic brain regions, such as the central nucleus of the amygdala (Swanson and Simmons, 1989; Makino et al., 1994; Watts and Sanchez-Watts, 1995).

The HPA axis is particularly sensitive to early experiences. In rat pups, manipulations, such as daily handling or maternal deprivation produce lifelong changes in stress reactivity, fearful behavior, and cognitive functioning (Levine, 1957; Meaney et al., 1988; Liu et al., 1997). Rodent models further suggest that prenatal stress has an impact that persists through adulthood. The offspring of stressed dams display prolonged glucocorticoid responses to stress indicating that exposure to stress in utero may impair negative feedback mechanisms (Weinstock et al., 1992; Henry et all, 1994; Herman and Cullinan, 1997). The offspring of rodents stressed during pregnancy also display an increase in behavioral signs of anxiety (Takahashi et al., 1992; Vallee et al., 1997). Alterations of CRH regulation in the amygdala is a proposed mechanism for this effect. The amygdala is considered to be the structure where fear-inducing sensory and autonomic input and behavioral output converge. Prenatally stressed rats display an increase in amygdala CRH (Cratty et al., 1995). Thus, elevations in amygdala $\mathrm{CRH}$, resulting from prenatal stress, may contribute to the increase in HPA axis reactivity and anxiety seen in these animals. Cognitive functions are also impaired in prenatally stressed animals. This may be particularly true for functions that are dependant on the hippocampus, a structure that is vulnerable to elevations in glucocorticoids (Takahashi, 1998; McEwen, 1999). In sum, these studies suggest that prenatal stress has lasting implications for CNS development and function.

Animal studies have offered valuable insights into physiological mechanisms that may be involved in mediating the effects of stressful maternal and intrauterine environments on the developing organism. However, the generalizability of these findings from animals to humans is limited by the existence of inter-species differences in physiology and the developmental time-line. The timing of maturation of the HPA axis relative to birth is highly species-specific and is closely linked to landmarks of brain development (Dobbing and Sands, 1979). In animals that give birth to precocious offspring (sheep, guinea pigs, primates), maximal brain growth and a large proportion of neuroendocrine maturation takes place in utero. By contrast, in species that give birth to non-precocious offspring (rats, rabbits, mice), much of neuroendocrine development occurs in the postnatal period (Dent et al., 2000). A second major difference is that anthropoid primates are the only species known to produce placental CRH during pregnancy.

The placenta expresses the genes for CRH (hCRHmRNA) and the preprotein for $\mathrm{ACTH}$ and $\beta \mathrm{E}$ (pro-opiomelanocortin, POMC). Placental CRH is identical to hypothalamic CRH in structure, immunoreactivity, and bioactivity (Petraglia et al., 1996). There is, however, one crucial difference in the regulation of hypothalamic and placental CRH. In contrast to the negative control on hypothalamic $\mathrm{CRH}$, glucocorticoids stimulate the expression of hCRHmRNA in the placenta creating a positive feedback loop that is similar to the central nucleus of the amygdala (Schulkin, 1999). Placental CRH is released into the maternal and fetal circulation, establishing a positive feedback loop that allows for the simultaneous increase of CRH, ACTH, and cortisol in the maternal and fetal compartments over the course of gestation (Petraglia et al., 1996; King et al., 2001).

The HPA-placental axis is a mechanism by which the environment shapes fetal development. The activity of the HPA-placental axis is regulated by characteristics of the maternal and intrauterine environment. Maternal cortisol, which crosses the placenta, increases with maternal stress (Wadhwa et al., 1996). Furthermore, in vitro and in vivo studies have demonstrated that placental CRH output is modulated in a positive, dose-response manner by the major biological effectors of stress, including cortisol (Korebrits et al., 1998; Marinoni et al., 1998). During pregnancy CRH levels were positively correlated with ACTH and $\beta E$ (Wadhwa et al., 1997). These findings support the premise that in human pregnancy placental CRH activity is modulated by maternal pituitary adrenal hormones. Both placental CRH and cortisol in turn may influence fetal development. Placental CRH is involved in the physiology of normal parturition and elevated CRH concentrations are associated with an increased risk for spontaneous preterm birth (McLean et al., 1995; Hobel et al., 1999a; Erickson et al., 2001; Holzman et al., 2001; Inder et al., 2001; Moawad et al., 2002). It has been proposed that the activity of the maternal-HPA-placental axis during pregnancy programs the development of the offspring's HPA axis (Ward and Phillips, 2001; Matthews, 2002). Additionally, placental $\mathrm{CRH}$ and cortisol may contribute to the organization of the fetal CNS (Sandman et al., 1997a; Florio and Petraglia, 2001). Few studies have considered the consequences of prenatal stress on human fetal behavior and fewer still have assessed the effects of maternal stress on the continuum between the fetus and the infant. We will discuss a neurobiological model of prenatal stress that proposes the developmental consequences of maternal psychosocial stress are mediated, in part, via maternal-placental-fetal neuroendocrine mechanisms. 


\section{Methodological approaches}

We have assessed the consequences of maternal stress during pregnancy on neuroendocrine processes and fetal and infant development using a range of techniques. Primarily, we have employed longitudinal population-based cohort studies with a combined sample of approximately 750 women with singleton, intrauterine pregnancies. Women were recruited at various time points in pregnancy starting in the late first or second trimester of gestation and followed through delivery into the early postpartum period. Participants were heterogeneous in terms of sociodemographic and ethnic characteristics. Furthermore, based on conventional measures of obstetric risk we have included approximately equal numbers of subjects at low- and high-risk for adverse perinatal outcomes. In these studies standardized and validated interviews and questionnaires were administered at multiple time points over gestation to assess:

(a) maternal psychosocial constructs including various forms of prenatal stress, social support, personality characteristics, and attitudes towards pregnancy;

(b) maternal behaviors including diet and nutrition, physical activity, and smoking, alcohol, and drug use;

(c) sociodemographic characteristics including age, marital status, various indicators of socioeconomic status, and race/ethnicity.

Maternal and cord blood samples were collected during gestation and a delivery for bioassays of stress hormones, including $\mathrm{ACTH}, \beta \mathrm{E}$, cortisol and placental CRH. Obstetric and birth outcomes were abstracted from the medical records. All pregnancies are dated by best obstetric estimate using last menstrual period and early ultrasonographic confirmation. In a sub sample of 156 pregnancies, we have performed fetal assessments in the early third trimester of gestation, including fetal biometry, doppler flow velocimetry of the uteroplacental circulation, and an experimental challenge paradigm to quantify indices of fetal arousal, reactivity, learning and habituation, assessed by fetal heart rate (FHR) responses to a series of vibroacoustic (VA) stimuli. To examine direct effects of glucocorticoids on fetal and infant HPA axis development, a sample of infants whose mother did or did not receive synthetic glucocorticoids during their pregnancy were recruited. In this population cortisol levels at baseline and in response to stress were assessed.

\section{Research findings}

Maternal stress during pregnancy and birth outcomes

Disruption of reproductive function in mammals is a well-known consequence of stress. Results from experimental approaches in animal models support a causal role for prenatal stress as a developmental teratogen (Weinstock, 2001). In humans, studies examining the influence of maternal stress during pregnancy have focused primarily on length of gestation and fetal growth/size at birth, the two primary indicators of newborn health. Using women's self report of stress during pregnancy we have found that maternal psychosocial processes significantly influence both length of gestation and fetal growth and that this influence is independent of the effects of other established sociodemographic and obstetric risk factors (Wadhwa et al., 1993; Rini et al., 1999; Feldman et al., 2000). Maternal stress has differential effects depending on its timing during pregnancy. From a prospective investigation of stress and stress physiology in pregnancy, 40 pregnant women were identified who had experienced a 6.8 magnitude earthquake during pregnancy or shortly after delivery. The participants lived, on average, 50 miles from the epicenter of the earthquake and were physically unaffected by the damage produced. The effect of exposure to the earthquake was linearly moderated by the stage in gestation of its occurrence. Women who experienced the earthquake earlier in their pregnancy had a significantly shorter gestational length than those who experienced it later in gestation (see Figure 6.1). This study supports the notion that the timing of stress in pregnancy may be an important factor in determining its impact on the length of human gestation (Glynn et al., 2001).

Our results are consistent with several population-based epidemiological studies that have suggested that high levels of maternal psychosocial stress are independently associated with a significant increase in the risk for prematurity and that effects are observed across the entire range of the outcome distribution (Hedegaard et al., 1993; Pritchard and Teo, 1994; Copper et al., 1996; Hedegaard et al., 1996; Misra et al., 2001). Additionally, the effect size of maternal psychosocial processes in pregnancy on prematurity-related outcomes is comparable to that of most other obstetric risk factors suggesting that these processes warrant the same degree of consideration.

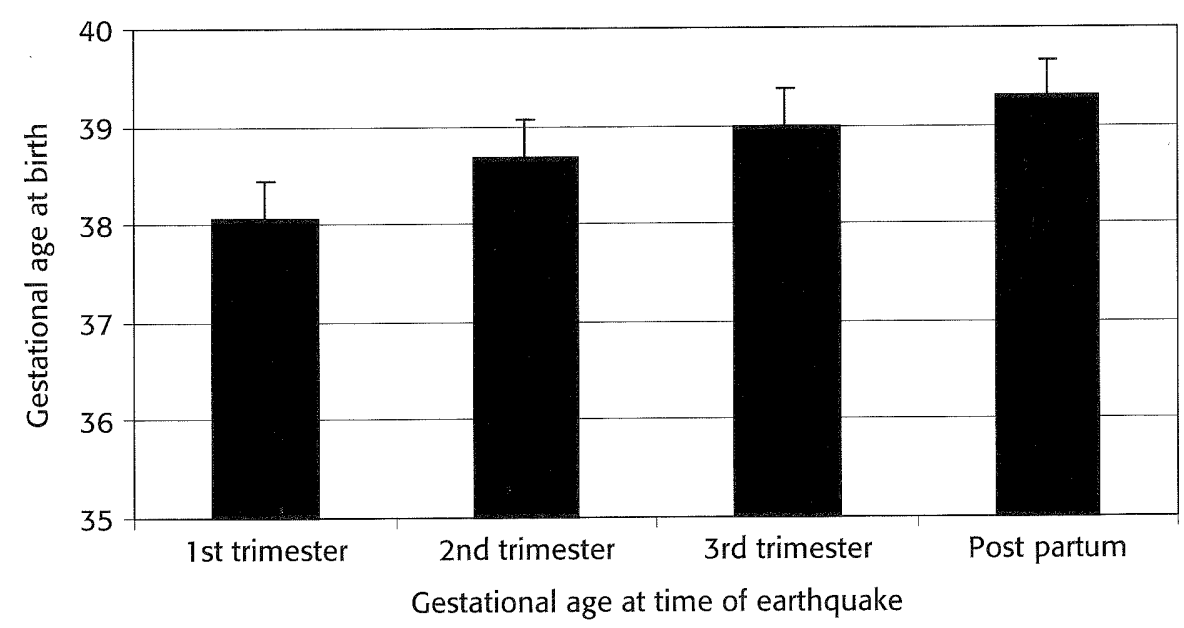

Figure 6.1 Stress during the first trimester of pregnancy significantly predicts shorter gestational length. Adapted from Glynn et al. (2001) 
Maternal stress during pregnancy and infant developmental outcomes

Maternal psychological state during pregnancy seems to influence birth outcome in terms of length of gestation and fetal growth. The influence of maternal experiences during pregnancy on the development of the fetal CNS and the implications for infant development has largely been neglected in human research. Existing research considering the effects of prenatal experience on postnatal development in humans is often limited by a failure to control for the effects of birth outcome. For example, infants born prematurely or small for gestational age (GA) are at risk for a wide variety of developmental problems (Peterson et al., 2003). It is necessary to consider these factors to examine the independent influence of prenatal stress physiology on postnatal development.

Recent studies suggest that maternal anxiety, stress and depression during pregnancy, shape the fetal behavioral patterns (DiPietro et al., 2002; Monk et al., 2003) and predict higher cortisol and norepinephrine and lower Brazelton scores in the newborn (Jones et al., 1998; Lundy et al., 1999). To examine whether this influence continued into infancy we conducted preliminary studies to prospectively assess the relationship between maternal stress during pregnancy and indices of infant behavioral development. Forty-seven mother-infant pairs were assessed during pregnancy and at 6 weeks after delivery. All infants in this sample were full term at birth. Questionnaires were administered to mothers to assess pre and postnatal maternal anxiety and infant temperament. Infant fussiness was associated with higher levels of maternal anxiety during the third trimester even after controlling for postpartum maternal affect, intrapartum compromise, infant sex and birth weight (Davis et al., 2003). These data are consistent with the few prospective studies present in the literature illustrating that maternal stress, anxiety, and depression during pregnancy is related to emotional disturbances and difficult temperament in the offspring (Van den Bergh, 1990; Susman et al., 2001; O'Connor et al., 2002a, b).

Subjective description of child behavior by the parent is confounded by the parent's psychological state at the time of reporting. One study identified an association between maternal anxiety during pregnancy and child behavior using a prospective design and objective behavioral observations of the child (Huizink et al., 2002). This study found that the infants of mothers who reported higher levels of anxiety during pregnancy displayed poorer attention regulation. Owing to the difficulty of conducting prospective studies, very few exist. There is a need for further prospective human studies that employ objective assessments of child behavior to elucidate the independent contribution of postnatal maternal psychological state on development.

To differentiate the effects of prenatal and postnatal maternal psychological state, maternal anxiety and depression were assessed prospectively. Infant behavioral reactivity was assessed at 4 months using a standardized laboratory-based behavioral assessment protocol (i.e. the Harvard Infant Behavioral Reactivity Protocol, Kagan and Snidman, 1991). In this paradigm infant motor and cry reactivity to a series of visual and auditory challenges were assessed. Maternal anxiety and depression during the third trimester of pregnancy, but not postpartum were associated with the development of individual differences in infants' behavioral regulation. The offspring of mothers who were higher in anxiety and depression during pregnancy displayed greater behavioral reactivity to novelty. Notably, this association remained after controlling for postpartum maternal psychological state indicating that prenatal experiences were responsible for this association (Davis et al., 2004a). The selective effects of prenatal experiences on behavioral reactivity supports the hypothesis that the prenatal environment exerts programming effects on the fetus with consequences for infant behavior (Barker, 2002). These data support a model that prenatal maternal stress has an independent effect not only on regulation of length of gestation but also on development of the fetus and thus the infant.

\section{Placental CRH and fetal growth and premature birth}

The maternal-HPA axis is one mechanism that has been proposed to mediate the effects of maternal stress during pregnancy on birth outcome and the development of the fetus. During pregnancy maternal ACTH and cortisol increases in response to stress in ways that are similar to the non-pregnant state (Wadhwa et al., 1996). Via this pathway, maternal stress can modulate placental CRH production. Placental $\mathrm{CRH}$ is involved in the physiology of parturition as well as fetal cellular differentiation, growth, and maturation (Challis et al., 2001; Smith, 2001; Hillhouse and Grammatopoulos, 2002). We have conducted several studies to examine the role of $\mathrm{CRH}$ in regulation of timing of delivery and fetal growth. The first study involved a sample of 63 women with singleton, intrauterine pregnancies. Maternal plasma was collected at 28-30 weeks gestation, and placental CRH concentrations were determined by radioimmuno assay. Results indicated that maternal (placental) $\mathrm{CRH}$ levels at 28-30 weeks gestation significantly and negatively predicted gestational length after adjusting for antepartum risk. Moreover, subjects who delivered prematurely (prior to 37 weeks gestation) had significantly higher CRH levels in the early third trimester than those who delivered at term (Wadhwa et al., 1998).

To explore further the associations between $\mathrm{CRH}$ and gestational length and to examine effects of $\mathrm{CRH}$ on fetal growth, 245 women with singleton, intrauterine pregnancies were recruited. Maternal plasma CRH was assessed at 32-33 weeks gestation. It was found that elevated $\mathrm{CRH}$ was related to both risk of preterm birth and fetal growth restriction. After adjusting for effects of established risk factors women with elevated CRH were approximately 3 times more likely to deliver 


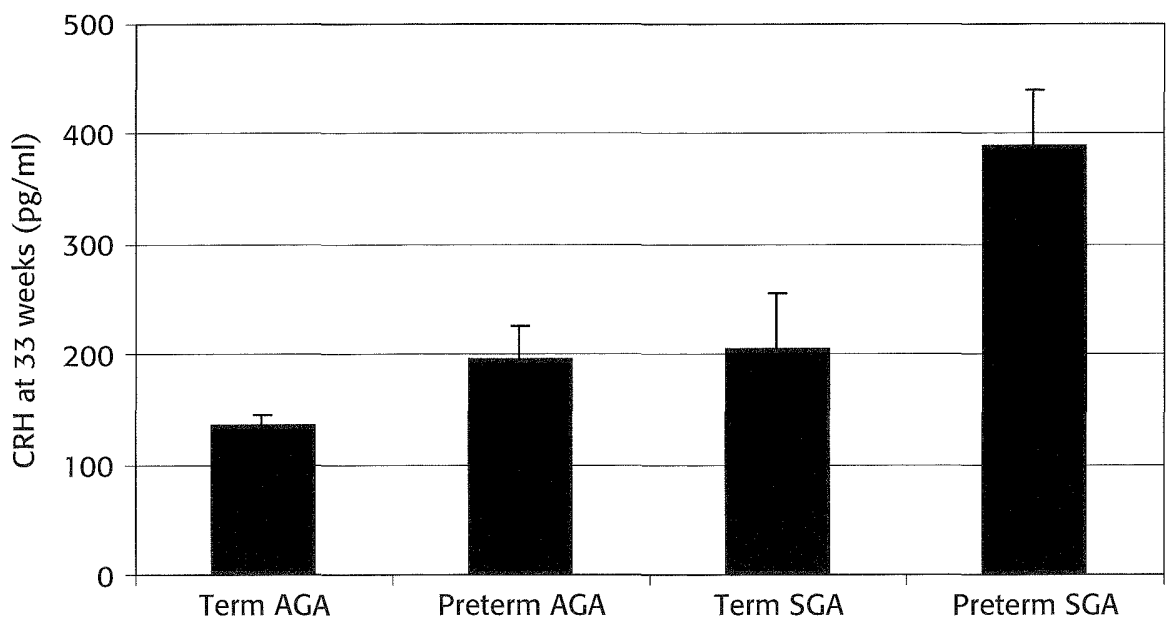

Figure 6.2 Infants born preterm or SGA more likely to be exposed to high levels of CRH during the third trimester of pregnancy. Adapted from Wadhwa et al. (2004). SGA: small for their gestational age; AGA: appropriate for gestational age

preterm and/or have an infant that was small for GA (see Figure 6.2; Wadhwa et al., 2004). The results of this study suggest that placental CRH plays a role in the physiology of parturition as well as in processes related to fetal growth.

These studies suggest that increased activity by the placental-HPA axis during the third trimester predicts premature labor. The question remains as to whether increased placental CRH earlier in pregnancy might also predict length of gestation. To address this issue CRH was assessed in 524 women at 18-20, 28-30, and 35-36 weeks gestation. Eighteen women with spontaneous premature labor were compared to 18 women who delivered at term. Patients who delivered prematurely had higher levels of CRH at all three measurement time points (Hobel et al., 1999a). Furthermore, women who delivered prematurely had lower levels of CRH-binding protein, which inactivates CRH (Hobel et al., 1999a). Thus, maternal $\mathrm{CRH}$ was elevated as early as $18-20$ weeks GA in woman who subsequently delivered prematurely.

\section{Neuroendocrine function during pregnancy and human fetal CNS development}

It has been proposed that the HPA-placental axis is a conduit for the effects of environmental stress on the fetus. Research with animals indicates that during prenatal development the hormones of the HPA axis have programming effects on the developing CNS (Matthews, 2000; Welberg and Seckl, 2001). The influerice of the maternal and intrauterine environment on the developing human fetal brain is poorly understood. This is in part, because the assessment and quantification of human fetal brain development presents theoretical and methodological challenges.

To quantify and examine the influence of the fetal environment on its brain development we have utilized a habituation-dishabituation paradigm that assesses the ability of the fetus to learn information. By 32 weeks gestation the fetus habituates and dishabituates to external stimulation (Sandman et al., 1997b). Faster fetal habituation has been associated with advancing GA (Shalev et al., 1990) consistent with maturation of the CNS. We examined the effect of maternal-placental $\mathrm{CRH}$ on habituation processes. Thirty-three pregnant women were assessed between 30 and 32 weeks gestation. Fetal heart rate and uterine contractions were assessed by placing transducers on the maternal abdomen. A total of 41 trials of vibroacoustic (VA) stimuli were presented over a 45 -min period. The first series of $15 \mathrm{VA}(63 \mathrm{~dB}, 300 \mathrm{~Hz})$ stimuli (S1) was presented on the maternal abdomen. On the 16th trial S2, the dishabituating VA stimuli $(68 \mathrm{~dB}, 400 \mathrm{~Hz}$, novel in frequency and intensity) was presented. The original VA stimuli (S1) was then presented for trials 17-31. As a control the final 10 stimuli were presented to the mother's thigh. The fetuses of mothers with highly elevated CRH levels did not respond significantly to the presence of the novel stimulus (Sandman et al., 1999). These data provide preliminary evidence that abnormally elevated levels of placental CRH may play a role in impaired neurodevelopment, as assessed by the degree of dishabituation (Sandman et al., 1999).

In addition to the effects of placental CRH on fetal CNS development described above, maternal pituitary and adrenal hormones may also shape fetal development. The influence of circulating maternal ACTH and $\beta E$ levels with measures of fetal responses to challenge was determined in a sample of 132 women at 31-32 weeks gestation. Fetal responses were measured by measuring heart rate (HR) habituation to a series of repeated VA stimuli. Individual differences in habituation were determined by computing the number of consecutive HR responses that were greater than the standard deviation of the HR during a control (non-stimulated) period. There was no significant relation between absolute levels of ACTH, $\beta E$ and fetal HR responses to challenge. However an index of POMC disregulation, the degree of uncoupling between $\mathrm{ACTH}$ and $\beta E$, was significantly related to fetal responses such that fetal exposure to relatively high levels of the maternal opiate, $\beta E$, relative to $\mathrm{ACTH}$, was associated with a significantly lower rate of habituation (see Figure 6.3; Sandman et al., 2003).

Our findings are consistent with those of longitudinal investigations of the functional development of the human fetal CNS over the course of gestation, that have suggested chronic maternal psychologic distress is significantly related to measures of fetal neurobehavioral maturation and reactivity (DiPietro et al., 1996; DiPietro et al., 2000; Monk et al., 2000; DiPietro et al., 2002; Monk et al., 2003). 


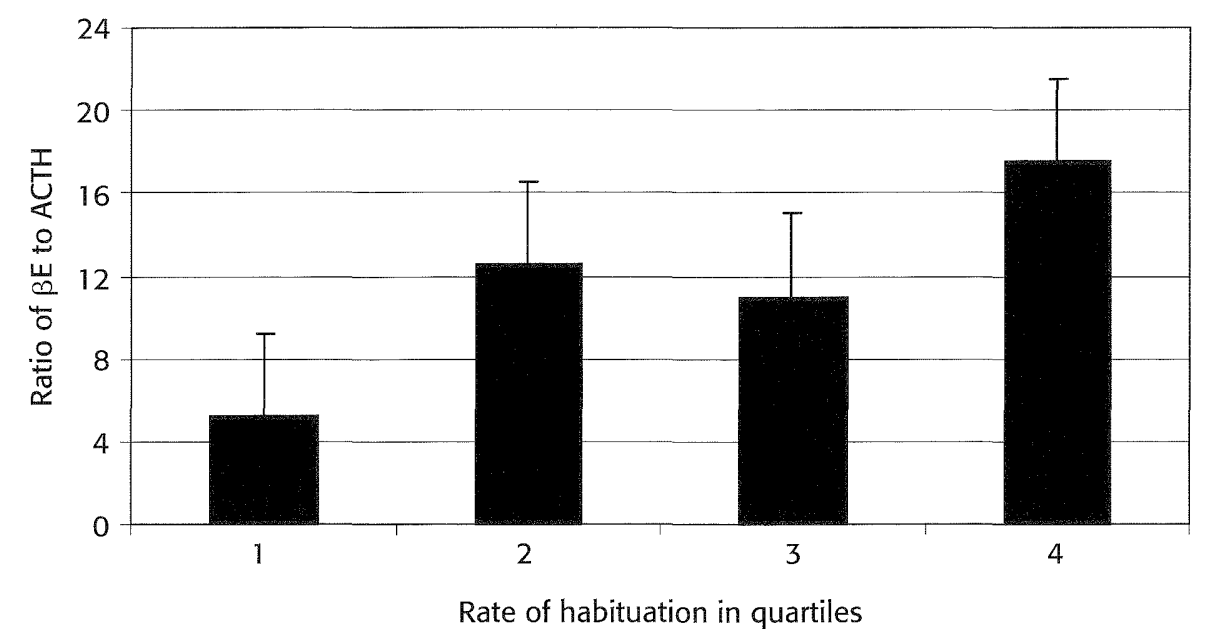

Rate of habituation in quartiles

Figure 6.3 Fetal exposure to relatively high levels of the maternal opiate, $\beta E$, relative to $A C T H$, is associated with a significantly lower rate of habituation. Adapted from Sandman et al. (2003)

The continuity of development from prenatal to postnatal development reguires further exploration.

\section{Endocrine hormones during pregnancy and human infant development}

Demonstration of an impact of maternal and placental hormones on fetal CNS functioning illustrates the importance of exploring the implications of fetal experiences on development in infancy and childhood. In rodents, primates and other species it has been shown that stimulation of the HPA axis or exposure to elevated glucocorticoids impairs brain development and HPA axis functioning in the offspring. There is transplacental passage of glucocorticoids to the fetus (Matthews et al., 2002). Animals exposed to prenatal elevations in glucocorticoids display impairments in brain development and increased reactivity to stress (Takahashi, 1998; Matthews et al., 2002; Antonow-Schlorke et al., 2003).

One method for examining the effects of HPA axis hormone disregulation on human infant development involves examination of the effects of administration of synthetic glucocorticoids to women during pregnancy. Antenatal glucocorticoid administration is a standard of care for women at risk of premature delivery and has been shown to reduce mortality and respiratory distress among preterm infants born at less than 34 weeks gestation. However, studies with humans have demonstrated that antenatal glucocorticoid exposure is associated with reduced birth weight (Banks et al., 1999; French et al., 1999) and head circumference
(French et al., 1999; Abbasi et al., 2000). Additionally prenatal glucocorticoid treatment effects postnatal HPA axis regulation in the offspring. Baseline cortisol levels are suppressed for 2-7 days after prenatal corticosteroid treatment and subsequently return to normal levels (Wittekind et al., 1993; Parker et al., 1996; Kauppila et al., 1978; Ballard et al., 1980; Dorr et al., 1989). These data suggest that prenatal exposure to elevated levels of glucocorticoids may have implications for infant development. The effect on the HPA axis response to stress has not, however, been assessed.

One of the sequelae of prenatal exposure to elevated glucocorticoids noted in the animal literature is disregulation of the HPA axis response to stress (Matthews, 2002). We thus examined the effects of prenatal glucocorticoid treatment on the cortisol response to stress during the first postnatal week in human infants born at 33-34 weeks with and without prenatal glucocorticoid treatment. Infants in the glucocorticoid group were on average 12 days post antenatal glucocorticoid treatment. Consistent with previous research demonstrating that baseline cortisol is suppressed only for the first 2-7 days after prenatal treatment, these two groups of infants did not differ in their resting baseline cortisol levels. Infants who were exposed to antenatal glucocorticoid, however, failed to mount a cortisol response to a painful stimulus, a heel-stick blood draw (see Figure 6.4). In contrast, premature infants who did not receive prenatal glucocorticoid treatment displayed an increase in cortisol in response to the heel-stick stressor (Davis et al., 2004b). This cortisol response, also displayed by full term infants, is considered appropriate and

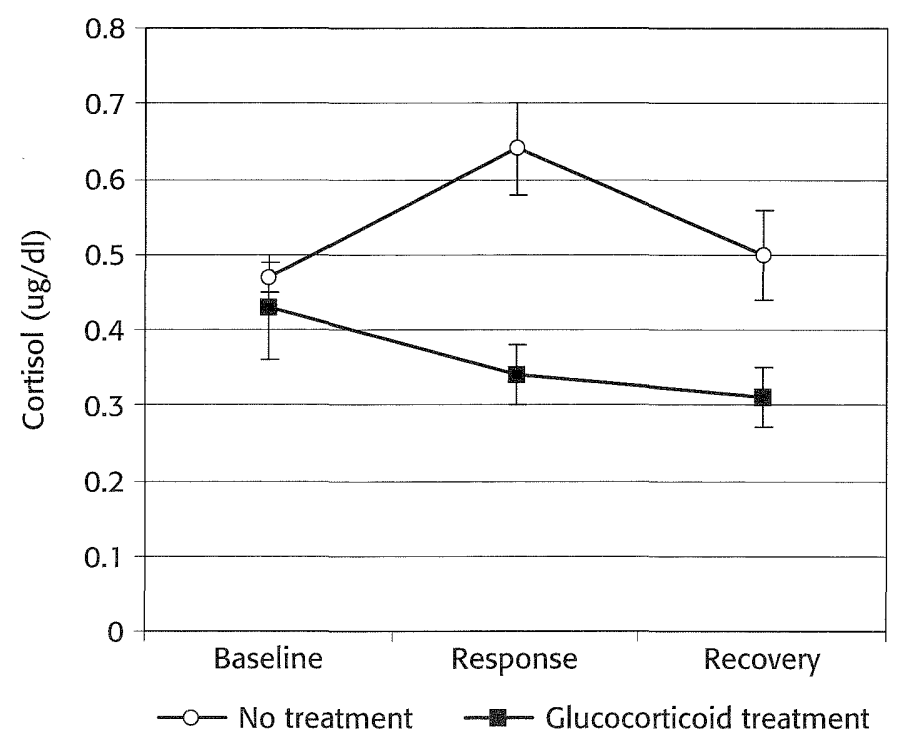

Figure 6.4 The cortisol response to a painful event is suppressed in infants with antenatal betamethasone treatment. Adapted from Davis et al. (2004b) 
supports adaptation to challenge (Gunnar, 1992). This study suggests that even after baseline cortisol levels have returned to normal levels the ability to respond to stress appears disregulated. This finding is consistent with data indicating that infants exposed to antenatal glucocorticoids displayed a suppressed response to the CRH stimulation test ( $\mathrm{Ng}$ et al., 2002).

Prenatal exposure to glucocorticoids seems to have a lasting effect on regulation of physiologic stress responses in the newborn. Furthermore, as groups were similar in GA at birth and prenatal history, prenatal glucocorticoid exposure appears to have a direct effect on postnatal stress physiology. We are currently conducting longitudinal studies to examine whether this disregulation of the HPA axis response to stress persists throughout infancy and early childhood.

\section{Conclusions and future directions}

Development is an epigenetic process by which, each developing organism plays an active role in its own construction. This dynamic process is affected by systems that are present during embryonic and fetal life to acquire information about the nature of the environment, and to use this information to guide development. Due to the rapid development that takes place during the prenatal period the fetus may be especially vulnerable to both organizing and disorganizing influences. These influences on the fetus have been described as programming, a process by which a stimulus or insult during a critical developmental period has a long-lasting or permanent influence (Nathanielsz, 1999). Animal models illustrate that maternal stress has programming influences on development that persist not only through adulthood, but may have transgenerational effects (Francis et al., 1999).

The human fetus is sensitive to the effects of maternal stress and furthermore these influences can be measured. Our program of research indicates that maternal activation of the HPA axis is associated with adverse birth outcomes and altered fetal responsiveness to stimulation. Additionally, prenatal stress and exposure to stress hormones has deleterious consequences for the developing infant. We have shown that while birth outcomes such as premature delivery can contribute to developmental impairments, stress and stress hormones have an independen effect on development. Our current projects extend these findings to understand the influence of the timing of stress on the fetus, the biological processes associated with stress and the pre- and postnatal developmental consequences of prenatal stress.

One objective is to extend our ability to predict adverse outcomes such as premature birth. The magnitude of the effect of prenatal stress is comparable to that of other established obstetric risk factors. The specificity and sensitivity of these measures as predictors of adverse outcome(s) in any individual pregnancy is modest. For example, low levels of placental CRH in pregnancy are a good negative predictor of preterm birth but high levels are a poor positive predictor. This may suggest that parameters such as stress and placental CRH should be considered in conjunction with other risk factors.

In addition to the maternal-placental-fetal neuroendocrine processes discussed above, host (maternal and/or fetal) proinflammatory immune responses produced by intrauterine or reproductive tract infection have been implicated in adverse fetal outcomes, especially extreme prematurity $(<30$ weeks gestation) and white matter brain damage (Romero et al., 2001). Although psychosocial stress is a wellestablished contributor to the risk of infection and its pathophysiological consequences (Cohen et al., 1999) and the endocrine and immune systems are known to extensively regulate and counter-regulate one another (McEwen et al., 1997; Shanks and Lightman, 2001; Elenkov and Chrousos, 2002), very little empirical work has been done to date to examine these interactions in the context of stress in pregnancy and fetal development. Thus, one of our current, ongoing studies is designed to examine psychoneuroendocrine-immune interactions in human pregnancy, to explore the hypothesis that maternal psychosocial stress and neuroendocrine stress responses may play a role in determining susceptibility to the development of reproductive tract infection and its pathophysiological consequences. We suggest this is a critical future direction for this work as the effect of either of these processes on a biological outcome of interest is modulated by the state/context of the other.

Returning to the concept of an epigenetic framework of development, it appears that embryonic and fetal developmental processes ultimately represent the dynamic interplay between two sets of information systems, fetal and maternal deoxyribonucleic acid (DNA) and the fetal and maternal environments. Genetic predispositions may make some pregnancies more vulnerable to environmental influences. We are not aware of any studies to date that have systematically examined the physiological genomics of maternal and fetal stress-related neuroendocrine systems and pathways in human pregnancy, and suggest this is yet another important future avenue for this line of research.

In conclusion, there is a compelling need to arrive at a better understanding of the determinants of individual differences in psychoneuroendocrine processes that underlie health and disease. The study of the interplay between biological and behavioral processes in fetal life, using a dynamic systems approach, holds great promise for our efforts to arrive at this understanding.

\section{REFERENCES}

Abbasi, S., Hirsch, D., Davis, J. et al. (2000). Effect of single versus multiple courses of antenatal corticosteroids on maternal and neonatal outcome. Am. J. Obstet. Gynecol., 182(5), 1243-9. 
Antonow-Schlorke, I., Schwab, M., Li, C. and Nathanielsz, P. W. (2003). Glucocorticoid exposure at the dose used clinically alters cytoskeletal proteins and presynaptic terminals in the fetal baboon brain. J. Physiol., 547(1), 117-23.

Ballard, P. L., Gluckman, P. D., Liggens, G. C., Kaplan, S. K. and Grumbach, M. M. (1980). Steroid and growth hormone levels in premature infants after prenatal betamethasone therapy to prevent respiratory distress syndrome. Pediatr. Res., 14, 122-7.

Banks, B. A., Cnaan, A., Morgan, M. A. et al. (1999). Multiple courses of antenatal corticosteroids and outcome of premature neonates. Am. J. Obstet. Gynecol., 181(3), 709-17.

Barker, D. J. (2002). Fetal programming of coronary heart disease. Trend Endocrinol. Metabolis., 13(9), 364-8.

Challis, J. R., Sloboda, D., Matthews, S. G. et al. (2001). The fetal placental hypothalamicpituitary-adrenal (HPA) axis, parturition and postnatal health. Mol. Cell. Endocrinol. 185(1-2), 135-44.

Chapillon, P., Patin, V., Roy, V., Vincent, A. and Caston, J. (2002). Effects of pre- and postnata stimulation on developmental, emotional, and cognitive aspects in rodents: a review. Develop. Psychobiol., 41(4), 373-87.

Chrousos, G. P. and Gold, P. W. (1992). The concept of stress and stress system disorders. J. Am Med. Assoc., 267(9), 1244-52.

Clarke, A. S., Wittwer, D. J., Abbott, D. H. and Schneider, M. L. (1994). Long-term effects of prenatal stress on HPA activity in juvenile rhesus monkeys. Develop. Psychobiol., 27(5), 257-69.

Cohen, S., Doyle, W. J. and Skoner, D. P. (1999). Psychological stress, cytokine production, and severity of upper respiratory illness. Psychosom. Med., 61(2), 175-80.

Copper, R. L., Goldenberg, R. L., Elder, N. et al. (1996). The preterm prediction study: materna stress is associated with spontaneous preterm birth at less than thirty-five weeks' gestation. Am. J. Obstet. Gynecol., 175, 1286-92.

Cratty, M. S., Ward, H. E., Johnson, E. A., Azzaro, A. J. and Birkle, D. L. (1995). Prenatal stress increases corticotropin-releasing factor $(\mathrm{CRF})$ content and release in rat amygdala minces. Brain Res., 675(1-2), 297-302.

Davis, E. P., Snidman, N., Wadhwa, P. D. et al. (2003). The impact of maternal psychological state during pregnancy on infant temperament. Develop. Psychobiol., 43(3), 252.

Davis, E. P., Snidman, N., Wadhwa, P. D. et al. (2004a). Prenatal maternal anxiety and depression predict behavioral reactivity in infancy. Infancy, 6(3), 319-31.

Davis, E. P., Townsend, E. L., Gunnar, M. R. et al. (2004b). Effects of prenatal corticosteroid exposure on regulation of stress physiology in healthy premature infants. Psychoneuroendocrinology, 29, 1028-36.

de Kloet, R., Vreugdenhil, E., Oitzl, M. S. and Joels, A. (1998). Brain corticosteroid receptor balance in health and disease. Endocr. Rev., 19(3), 269-301.

Dent, G. W., Smith, M. A. and Levine, S. (2000). Rapid induction of corticotropin-releasing hormone gene transcription in the paraventricular nucleus of the developing rat. Endocrinology, 141(5), 1593-8.

DiPietro, J. A., Hodgson, D. M., Costigan, K. A. and Johnson, T. R. (1996). Fetal antecedents of infant temperament. Child Develop., 67(5), 2568-83.
DiPietro, J. A., Costigan, K. A., Pressman, E. K. and Doussard-Roosevel, J. A. (2000). Antenatal origins of individual differences in heart rate. Develop. Psychobiol., 37(4), 221-8.

DiPietro, J. A., Hilton, S. C., Hawkins, M., Costigan, K. A. and Pressman, E. K. (2002). Maternal stress and affect influence fetal neurobehavioral development. Develop. Psychol, 38(5), 659-68.

Dobbing, J. and Sands, J. (1979). Comparative aspects of the brain growth spurt. Early Hum. Develop., 3(1), 79-83.

Dorr, H. G., Heller, A., Versmold, H. T. et al. (1989). Longitudinal study of progestins, mineralocorticoids, and glucocorticoids throughout human pregnancy. J. Clin. Endocrinol. Metabolis., 68(5), 863-868.

Elenkov, I. J. and Chrousos, G. P. (2002). Stress hormones, proinflammatory and antiinflammatory cytokines, and autoimmunity. Ann. New York Acad. Sci., 966, 290-303.

Erickson, K., Thorsen, P., Chrousos, G. et al. (2001). Preterm birth: associated neuroendocrine, medical and behavioral risk factors. J. Clin. Endocrinol. Metabolis., 86(6), 2544-52.

Feldman, P. J., Dunkel Schetter, C., Sandman, C. A. and Wadhwa, P. D. (2000). Maternal social support predicts birth weight and fetal growth in human pregnancy. Psychosom. Med., 62, 715-25.

Florio, P. and Petraglia, F. (2001). Human placental corticotropin releasing factor (CRF) in the adaptive response to pregnancy. Stress, 4, 247-61.

Francis, D., Diorio, J., Liu, D. and Meaney, M. J. (1999). Nongenomic transmission across generations of maternal behavior and stress responses in the rat. Science, 286(5442), 1155-8.

French, N., Hagan, R., Evans, S. F., Godfrey, M. and Newnham, J. (1999). Repeated antenatal corticosteroids: size at birth and subsequent development. Am. J. Obstet. Gynecol., 180, 114-21.

Glynn, L., Wadhwa, P. D., Dunkel Schetter, C. and Sandman, C. A. (2001). When stress happens matters: the effects of earthquake timing on stress responsivity in pregnancy. Am. J. Obstet. Gynecol., 184, 637-42.

Gunnar, M. R. (1992). Reactivity of the hypothalamic-pituitary-adrenocortical system to stressors in normal infants and children. Pediatrics, 90(3), 491-7.

Hedegaard, M., Henriksen, T. B., Sabroe, S. and Secher, N. J. (1993). Psychological distress in pregnancy and preterm delivery. Brit. Med. J., 307, 234-9.

Hedegaard, M., Henriksen, T. B., Secher, N. J., Hatch, M. C. and Sabroe, S. (1996). Do stressful life events affect duration of gestation and risk of preterm delivery? Epidemiology, 7(4), 339-45.

Henry, C., Kabbaj, M., Simon, H., LeMoal, M. and Maccari, S. (1994). Prenatal stress increases the hypothalamio-pituitary-adrenal axis response in young and adult rats. J. Neuroendocrinol., 6(3), 341-5.

Herman, J. P. and Cullinan, W. E. (1997). Neurocircuitry of stress: central control of the hypothalamio-pituitary-adrenocortical axis. Trend. Neurosci., 20(2), 78-84.

Hillhouse, E. W. and Grammatopoulos, D. K. (2002). Role of stress peptides during human pregnancy and labor. Reproduction, 124(3), 323-9.

Hobel, C. J., Dunkel-Schetter, C., Roesch, S. C., Castro, L. C. and Arora, C. P. (1999). Maternal plasma corticotropin-releasing hormone associated with stress at 20 weeks gestation in pregnancies ending in preterm delivery. Am. J. Obstet. Gynecol., 180(1 Pt 3), 257-63.

Holzman, C., Jetton, J., Siler-Khodr, T., Fisher, R. and Rip, T. (2001). Second trimester corticotropinreleasing hormone levels in relation to preterm delivery and ethnicity. Obstet. Gynecol., 97, $657-63$. 
Huizink, A. C., De Medina, P. G., Mulder, E. J., Visser, G. H. and Buitelaar, J. K. (2002). Psychological measures of prenatal stress as predictors of infant temperament. J. Am. Acad. Child and Adolescent Psychiat., 41(9), 1078-85.

Inder, W. J., Prickett, T. C., Ellis, M. J. et al. (2001). The utility of plasma CRH as a predictor of preterm delivery. J. Clin. Endocrinol. Metabolis., 86(12), 5706-10.

Jacobson, L. and Sapolsky, R. (1991). The role of the hippocampus in feedback regulation of the hypothalamic pituitary adrenocortical axis. Endocr. Rev., 12(2), 118-34.

Jones, N. A., Field, T., Fox, N. A. et al. (1998). Newborns of mothers with depressive symptoms are physiologically less developed. Infant Behav. Develop., 21(3), 537-41.

Kagan, J. and Snidman, N. (1991). Temperamental factors in human development. Am. Psychol., $46,856-62$.

Kauppila, A., Koivisto, M., Pukka, M. and Tuimala, R. (1978). Umbilical cord and neonatal cortisol levels. Effect of gestational and neonatal factors. Obstet. Gynecol., 52(6), 666-72.

King, B. R., Smith, R. and Nicholson, R. C. (2001). The regulation of human corticotrophinreleasing hormone gene expression in the placenta. Peptides, 22(11), 1941-7.

Korebrits, C., Yu, D. H., Ramirez, M. M. et al. (1998). Antenatal glucocorticoid administration increases corticotrophin-releasing hormone in maternal plasma. Brit. J. Obstet. Gynecol., 105(5), 556-61.

Levine, S. (1957). Infantile experience and resistance to physiological stress. Science, 126, 405-6.

Liu, D., Diorio, J., Tannenbaum, B. et al. (1997). Maternal care, hippocampal glucocorticoid receptors, and hypothalamic-pituitary-adrenal responses to stress. Science, 277, 1659-62.

Lundy, B. L., Jones, N. A., Field, T. et al. (1999). Prenatal depression effects on neonates. Infant Behav. Develop., 22(1), 119-29.

Makino, S., Gold, P. W. and Scchulkin, J. (1994). Effects of corticosterone on CRH mRNA and content in the central nucleus and the parvocellular region of the paraventricular nucleus of the hypothalamus. Brain Res., 640, 105-12.

Marinoni, E., Korebrits, C., Di Lorio, R., Cosmi, E. V. and Challis, J. R. (1998). Effect of betamethasone in vivo on placental corticotropin-releasing hormone in human pregnancy. Am. J. Obstet. Gynecol., 178(4), 770-8

Matthews, S. G. (2000). Antenatal glucocorticoids and programming of the developing CNS. Pediatr. Res., 47(3), 291-300.

Matthews, S. G. (2002). Early programming of the hypothalamo-pituitary-adrenal axis. Trend. Endocrinol. Metab., 13(9), 373-80.

Matthews, S. G., Owen, D., Benjamin, S. and Andrews, M. H. (2002). Glucocorticoids, hypothalamo-pituitary-adrenal (HPA) development, and life after birth. Endocr. Res., 28(4), 709-18. McEwen, B. S. (1999). Stress and hippocampal plasticity. Annu. Rev. Neurosci., 22, 105-22.

McEwen, B. S., Biron, C. A., Brunson, K. W. et al. (1997). The role of adrenocorticoids as modulators of immune function in health and disease: neural, endocrine, and immune interactions. Brain Res. Rev., 23(1-2), 79-133.

McLean, M., Bisits, A., Davies, J. et al. (1995). A placental clock controlling the length of human pregnancy. Nat. Med., 1, 460-3.

Meaney, M. J., Aitken, D. H., Van Berkel, C., Bhatnagar, S. and Sapolsky, R. M. (1988). Effect of neonatal handling on age-related impairments associated with the hippocampus. Science, 239, 766-8.
Misra, D. P., O'campo, P. and Strobino, D. (2001). Testing a sociomedical model for preterm delivery. Pediatr. Perinatol. Epidemiol., 15, 110-22.

Moawad, A. H., Goldenberg, R. L., Mercer, B. et al. (2002). The preterm prediction study: the value of serum alkaline phosphatase, alpha-fetoprotein, plasma corticotropin-releasing hormone, and other serum markers for the prediction of spontaneous preterm birth. Am. J. Obstet. Gynecol., 186(5), 990-6.

Monk, C., Fifer, W. P., Myers, M. M. et al. (2000). Maternal stress responses and anxiety during pregnancy: effects on fetal heart rate. Develop. Psychobiol., 36(1), 67-77.

Monk, C., Myers, M. M., Sloan, R. P., Ellman, L. M. and Fifer, W. P. (2003). Effects of women's stress-elicited physiological activity and chronic anxiety on fetal heart rate. J. Develop. Behav. Pediatr., 24(1), 32-8.

Munck, A., Guyre, P. M. and Holbrook, N. J. (1984). Physiological functions of glucocorticoids in stress and their relation to pharmacological actions. Endocr. Rev., 5(1), 25-44.

Nathanielsz, P. W. (1999). Life in the Womb: The Origin of Health and Disease. Ithaca, New York: Promethean Press.

Ng, P. C., Lam, C. W., Lee, C. H. et al. (2002). Reference range and factors affecting the human corticotropin-releasing hormone test in preterm, very low birth weight infants. J. Clin. Endocrinol. Metabolis., 87(10), 4621-8.

O'Connor, T. G., Heron, J. and Glover, V. (2002a). Antenatal anxiety predicts child behavioral/emotional problems independently of postnatal depression. J. Am. Acad. Child Adolescent Psychiat., 41(12), 1470-7.

O'Connor, T. G., Heron, J., Golding, J., Beveridge, M. and Glover, V. (2002b). Maternal antenata anxiety and children's behavioural/emotional problems at 4 years: report from the Avon longitudinal study of parents and children. Brit. J. Psychiat., 180, 502-8.

Parker, C. R. J., Atkinson, M. W., Owen, J. and Andrews, W. W. (1996). Dynamics of the fetal adrenal, cholesterol, and apolipoprotein B responses to antenatal betamethasone therapy. Am. J. Obstet. Gynecol., 174(2), 562-5.

Peterson, B. S., Anderson, A. W., Ehrenkranz, R. et al. (2003). Regional brain volumes and their later neurodevelopmental correlates in term and preterm infants. Pediatrics, 111(5), 939-48.

Petraglia, F., Florio, P., Nappi, C. and Genazzani, A. R. (1996). Peptide signaling in human placenta and membranes: autocrine, paracrine, and endocrine mechanisms. Endocr. Rev., 17, 156-86.

Pritchard, C. W. and Teo, P. Y. (1994). Preterm birth, low birthweight and the stressfulness of the household role for pregnant women. Soc. Sci. Med., 38, 89-96.

Rini, C. K., Dunkel Schetter, C., Wadhwa, P. D. and Sandman, C. A. (1999). Psychological adaptation and birth outcomes: the role of personal resources, stress and sociocultural context during pregnancy. Health Psychol., 18, 333-45.

Romero, R., Gomez, R., Chaiworapongsa, T. et al. (2001). The role of infection in preterm labour and delivery. Pediatr. Perinatal Epidemiol., 15(S2), 41-56

Sanchez, M. M., Young, L. J., Plotsky, P. M. and Insel, T. R. (2000). Distribution of corticosteroid receptors in the rhesus brain: relative absence of glucocorticoid receptors in the hippocampal formation. J. Neurosci., 20(12), 4657-68.

Sandman, C. A., Wadhwa, P. D., Chicz-DeMet, A., Dunkel-Schetter, C. and Porto, M. (1997a). Maternal stress, HPA activity, and fetal/infant outcome. Ann. New York Acad. Sci., 814, 266-75. 
Sandman, C. A., Wadhwa, P. D., Hetrick, W., Porto, M. and Peeke, H. V. S. (1997b). Human fetal heart rate dishabituation at thirty-two weeks gestation. Child Develop., 68, 1031-40.

Sandman, C. A., Wadhwa, P. D., Chicz-DeMet, A., Garite, T. J. and Porto, M. (1999). Maternal corticotropin-releasing hormone $(\mathrm{CRH})$ influences heart rate reactivity to challenge in human pregnancy. Develop. Psychobiol., 34(3), 163-73.

Sandman, C., A., Glynn, L., Wadhwa, P. D. et al. (2003). Maternal hypothalamic-pituitaryadrenal disregulation during the third trimester influences human fetal responses. Develop. Neurosci., 25, 41-9.

Schneider, M. L. (1992). Prenatal stress exposure alters postnatal behavioral expression under conditions of novelty challenge in rhesus monkey infants. Develop. Psychobiol., 25(7), 529-40.

Schneider, M. L. and Coe, C. L. (1993). Repeated social stress during pregnancy impairs neuromotor development of the primate infant. J. Develop. Behav. Pediatr., 14, 81-7.

Schneider, M. L., Coe, C. L. and Lubach, G. R. (1992). Endocrine activation mimics the adverse effects of prenatal stress on the neuromotor development of the infant primate. Develop. Psychobiol., 25(6), 427-39.

Schneider, M. L., Roughton, E. C., Koehler, A. J. and Lubach, G. R. (1999). Growth and development following prenatal stress exposure in primates: an examination of ontogenetic vulnerability. Child Develop., 70(2), 263-74.

Schulkin, J. (1999). CRH in allostatic overload. J. Endocrinol., 161, 349-56.

Shalev, E., Benett, M. J., Megory, E., Wallace, R. M. and Zuckerman, H. (1990). Fetal habituation to sound stimulus in various behavioral states. Gynecol. Obstet. Invest., 29, 115-17.

Shanks, N. and Lightman, S. L. (2001). The maternal-neuronatal neuro-immune interface: are there long-term implications for inflammatory or stress-related disease? J. Clin. Invest., 108(11), 1567-73.

Smith, R. (2001). The Endocrinology of Parturition. Newcastle, Australia: Karger.

Susman, E. J., Schmeelk, K. H., Ponirakis, A. and Gariepy, J. L. (2001). Maternal prenatal, postpartum, and concurrent stressors and temperament in 3-year-olds: a person and variable analysis. Develop. Psychopathol., 13(3), 629-52.

Swanson L. W., Simmons, D. M. (1989). Differential steroid hormone and neural influences on peptide mRNA levels in corticotropin-releasing hormone cells of the paraventricular: hybridization histochemical study in the rat. J. Comp. Neurol., 285, 413-35.

Takahashi, L. K. (1998). Prenatal stress: consequences of glucocorticoids on hippocampal development and function. Int. J. Develop. Neurosci. 16(3), 199-207.

Takahashi, L. K., Turner, J. G. and Kalin, N. H. (1992). Prenatal stress alters brain catecholaminergic activity and potentiates stress-induced behavior in adult rats. Brain Res., 514, 131-7.

Vallee, M., Mayo, W., Dellu, F. et al. (1997). Prenatal stress induces high anxiety and postnata handling induces low anxiety in adult offspring: correlation with stress-induced corticosterone injection. J. Neurosci., 17, 2626-36.

Van den Bergh, B. (1990). The influence of maternal emotion during pregnancy on fetal and neonatal behavior. Pre- Peri-natal Psychol., 5(2), 119-30.

Wadhwa, P. D., Sandman, C. A., Porto, M., Dunkel Schetter, C. and Garite, T. J. (1993). The association between prenatal stress and infant birth weight and gestational age at birth: a prospective investigation. Am. J. Obstet. Gynecol., 169, 858-65.
Wadhwa, P. D., Dunkel Schetter, C., Chicz-DeMet, A., Porto, M. and Sandman, C. A. (1996). Prenatal psychosocial factors and the neuroendocrine axis in human pregnancy. Psychosom. Med., 58, 432-46.

Wadhwa, P. D., Sandman, C. A., Chicz-DeMet, A. and Porto, M. (1997). Placental CRH modulates maternal pituitary-adrenal function in human pregnancy. Ann. New York Acad. Sci., 814, 276-81.

Wadhwa, P. D., Porto, M., Garite, T. J., Chicz-DeMet, A. and Sandman, C. A. (1998). Maternal corticotropin-releasing hormone levels in the third trimester predict length of gestation in human pregnancy. Am. J. Obstet. Gynecol., 179, 1079-85.

Wadhwa, P. D., Garite, T. J., Porto, M. et al. (2004). Placental corticotropin-releasing hormone $(\mathrm{CRH})$, Spontaneous preterm birth and fetal growth restriction: a prospective investigation. Am. J. Obstet. Gynecol, 191, 1063-9.

Ward, A. M. V. and Phillips, D. J. W. (2001). Fetal programming of stress responses. Stress, 4, 263-71.

Watts, A. G., Sanchez-Watts, G. (1995). Region specific regulation of neuropeptide mRNAs in rat limbic forebrain neurones by aldosterone and corticosterone. J. Physiol., 484, 721-36.

Weinstock, M. (2001). Alterations induced by gestational stress in brain morphology and behaviour of the offspring. Prog. Neurobiol., 65, 427-51.

Weinstock, M., Matlina, E., Maor, G. I., Rosen, H. and McEwen, B. S. (1992). Prenatal stress selectively alters the reactivity of the hypothalamic-pituitary adrenal system in the female rat. Brain Res., 595, 195-200.

Welberg, L. A. and Seckl, J. (2001). Prenatal stress, glucocorticoids and the programming of the brain. J. Neuroendocrinol., 191, 1063-106913,113-28.

Wittekind, C. A., Arnold, J. D., Leslie, G. I., Luttrell, B. and Jones, M. P. (1993). Longitudinal study of plasma ACTH and cortisol in very low birth weight infants in the first 8 weeks of life. Early Hum. Develop., 33(3), 191-200.

Zarrow, M. X., Philpott, J. E. and Denenberg, V. H. (1970). Passage of 14-C-4 Corticosterone from the rat mother to the fetus and neonate. Nature, 226, 1058-9. 